\title{
Recurrent Parotid Gland Carcinoma
}

National Cancer Institute

\section{Source}

National Cancer Institute. Recurrent Parotid Gland Carcinoma. NCI Thesaurus. Code C153800.

The reemergence of parotid gland carcinoma after a period of remission. 